\title{
Visualización Analógica para Animaciones Digitales de Arquitectura - La Técnica del Folioscopio
}

\author{
Analog Visualization for Digital Animation of Architecture - The Technique of Flip book
}

\author{
> Felipe Etchegaray Heidrich \\ Universidade Federal de Pelotas, Brasil \\ felipeheidrich@gmail.com
}

\author{
> Ernesto Redondo \\ Universidad Politécnica de Cataluña, España \\ ernesto.redondo@upc.edu
}

\begin{abstract}
This paper proposes a method for the use the traditional animation technique, the flip book, to analog visualization of motions developed from digital media. Then, the study proposes a method of developing flip books from animations generated with the software Sketchup. With the development of examples the study shows the possibility of representation of motion on representations in paper, and that these motions can be generated from a digital three-dimensional model.
\end{abstract}

Keywords: Analog Visualization, Digital Animation, Flip book, Architectural Representation.

\section{Introducción}

El presente estudio es parte de una investigación que empezó con un análisis (Heidrich y Redondo, 2011), que tenía como objetivo confirmar o contrariar la percepción inicial de que mismo que el uso de representaciones digitales ya conste del cotidiano de las escuelas de arquitectura, sigue el predominio de las representaciones planas y estáticas utilizadas desde siempre. Para esto, fue elegido un universo limitado a una escuela de arquitectura en Brasil, la Faculdade de Arquitetura e Urbanismo (FAUrb) de la Universidade Federal de Pelotas (UFPel), donde fueron aplicados cuestionarios a profesores y alumnos.

Los datos obtenidos identificaron y confirmaron el predominio de representaciones planas y estáticas como medio de representación y análisis de proyecto arquitectónico, mismo con la predominancia de la utilización de representaciones desarrolladas en medio digital. Estos datos originaron una investigación con objetivo de proponer el uso de representaciones con características de movimiento e interactividad en el análisis visual de proyectos arquitectónicos en el medio académico. La parte del estudio a que se refiere este texto, tiene relación con la etapa de la investigación que propone un método de inclusión de movimiento en las representaciones en papel.

De este modo, el presente texto propone y describe un método para la utilización del folioscopio como una visualización analógica para animaciones desarrolladas con contenido digital, las cuales tienen su visualización normalmente dependiente de algún equipamiento electrónico.

\section{Representación Gráfica Arquitectónica}

El movimiento, mismo que parte de una ilusión, es algo que debería estar siempre presente en las representaciones arquitectónicas, pues como observa Bloomer (1982), "cualquier arquitectura es un estímulo potencial del movimiento, sea este real, o imaginado” (p. 72). Para el autor, un edificio es "un estimulante para la acción, un escenario en el que tienen lugar la interacción y el movimiento" (p. 72).

En este sentido, Sainz (1990) comenta que "la experiencia de la arquitectura en general, y del espacio arquitectónico en particular, se caracteriza por ser dinámica, continua y variable. Cuando recorremos un edificio o una ciudad, lo hacemos de un modo dinámico, moviéndonos a lo largo de calles y plazas o en el interior de las construcciones" (p. 69).

Esta dinámica, característica de la visualización arquitectónica, es una característica también necesaria en la representación gráfica, como observa Arnheim (1954), "representar un objeto significa mostrar algunas de sus propiedades particulares." (p. 170). Para Montes (1992), lo habitual en el arte de representación es la información, por lo tanto, "hemos de entender que una función de toda representación es la descripción” (p. 64).

Esta descripción, objetivo de la representación gráfica de objetos arquitectónicos, debe proporcionar una experiencia arquitectónica lo más compatible posible con el objeto que representa. Siendo así, según comenta Norberg-Schulz (1998), "es natural definir la verdadera experiencia arquitectónica como la percepción de la totalidad arquitectónica”. (p. 125). Parece evidente que, para una experiencia visual arquitectónica consistente, debemos tener juntos 
la percepción visual y el movimiento, esto en una construcción real o en una representación.

Sin embargo, según comenta Sainz (1990), "la representación del espacio arquitectónico se ve restringida por las propiedades del medio gráfico en que se desenvuelve" (p. 30). Así que la visualización arquitectónica analógica representada por medios gráficos en papel habitualmente significa la utilización de representaciones estáticas. Lo que ocurre es que a menudo estas representaciones estáticas son generadas digitalmente y con origen en modelos tridimensionales, los cuales podrían ser utilizados para generar animaciones digitales.

\section{Animación Digital}

La primera operación para el desarrollo de una escena digital es la etapa del modelado geométrico digital, que consiste en representar la forma geométrica del objeto deseado en el espacio digital. Además del modelado digital tener la capacidad de generar objetos, el autor Monedero (1999) comenta que su potencialidad de modo principal, está en la capacidad de modificar y combinar estos objetos.

De esta manera, según Monedero (1999), una vez generado un elemento tridimensional, podemos mover este elemento para situarlo en otra posición o para obtener un nuevo elemento, podemos girar este elemento, podemos invertir el dicho elemento y podemos modificar su escala para adaptarlo a un nuevo contexto. Así, con la utilización de algunas de estas modificaciones, y con la definición de algunas posiciones llaves (keyframes) podemos obtener una animación digital.

En este sentido, según comenta Júnior (2005), la simulación de la técnica del Keyframe en la animación digital busca reproducir con exactitud el procedimiento verificado en la animación clásica: el animador jefe dibuja las posiciones principales (key positions) de una secuencia del movimiento, para que el animador asistente desarrolle dibujos que llenen los intervalos entre estas posiciones principales. Así, el software gráfico utilizado va a responder exactamente por el desarrollo de los dibujos intermediarios por medio de un proceso conocido por interpolación.

Por lo tanto, según Júnior (2005), cuando definidos los keyframes y los demás parámetros de la animación digital, la herramienta gráfica, a través de un algoritmo de interpolación, calculará las posiciones del objeto en el espacio digital, haciendo los cambios que correspondan a las diferencias de parámetros entre dos keyframes.

Mismo que el desarrollo de una animación digital pueda ser, a través de la utilización del proceso de interpolación, de desarrollo sencillo, su visualización estará restringida a utilización de un dispositivo electrónico, lo que dificulta su utilización en representaciones analógicas, o sea, en papel.

De este modo, este estudio buscó identificar una técnica de visualización de animación que hiciera posible la visualización en papel de una animación desarrollada en medio digital, identificando como una posibilidad el uso del folioscopio.

\section{La Técnica Del Folioscopio}

Según Comalada (2008), el folioscopio - del latín "folium”, hoja y del griego "skopein", examinar - es un pequeño libro formado por una serie de imágenes ordenadas, destinado a ser mirado con

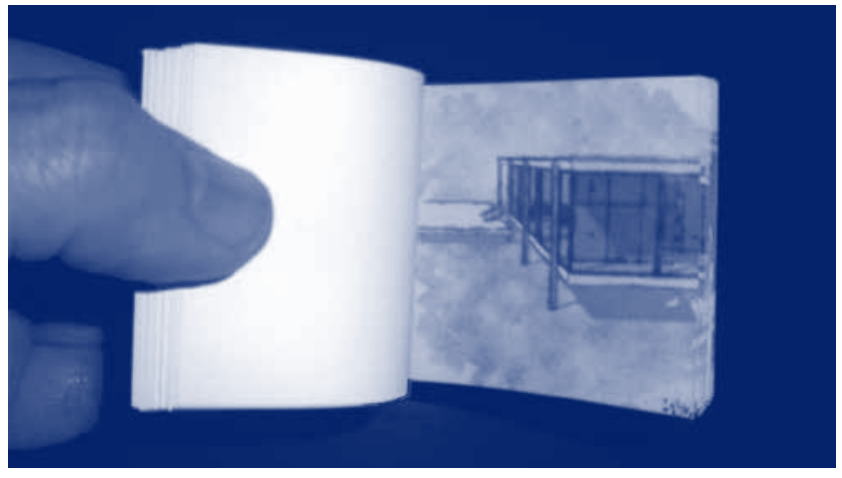

Figura l: Ejemplo de un Folioscopio desarrollado por el estudio

cierta rapidez para dar una impresión de movimiento, una ilusión procesada en nuestro cerebro.

No es posible datar la aparición de la técnica con precisión, pero se sabe que hace parte del conjunto de juguetes u objetos ópticos que se preceden a la aparición del cine y que cubren el proceso evolutivo entre la fotografía y el cine: el llamado pre-cine. Así que su utilización consiste en una visualización analógica, por tratarse de imágenes en papel y estáticas, pero que nos posibilita una ilusión de movimiento.

El autor Dupeyrot (1981) comenta que el folioscopio o flip book es como si fuera una película sin los equipamientos habituales del cine, y desde su aparición se percibió la posibilidad de producir lo que se puede llamar de "cine de pulgar", esto porque para ver la animación se sostiene el folioscopio con una mano y con el pulgar de la otra se le da la "acción" a la película.

En este sentido, el presente estudio propone un método para la utilización de esta técnica de animación tradicional, el folioscopio, como artificio de visualización analógica para movimientos desarrollados en medio digital.

\section{Folioscopio con Contenido de Animación Digital}

Como dicho al principio, este estudio hace parte de una investigación más grande que propone la inserción de movimiento e interactividad en las representaciones de proyectos arquitectónicos desarrollados por estudiantes de arquitectura. Sin embargo, la idea es hacer uso de representaciones ya habitualmente desarrolladas por ellos. Con este objetivo, el presente estudio partió de un tipo de modelo digital desarrollado a menudo por los estudiantes de la escuela en que se hizo el estudio, o sea, modelo tridimensional desarrollado en Sketchup. Así que él método propuesto para la visualización analógica de animaciones digitales consiste en:

1. Definición de Keyframes: el software Sketchup no tiene muchas propiedades de animación, lo único que él hace (sin añadir otros plugins), es la interpolación entre cámara y planos de sección. Así, para generar la animación es necesario la definición de algunas escenas, que en el Sketchup es interpretado como definición de Keyframes para que sea posible el desarrollo de las interpolaciones deseadas.

2. Desarrollo de la secuencia de imágenes estáticas: con la animación definida, esta necesita ser exportada como un 


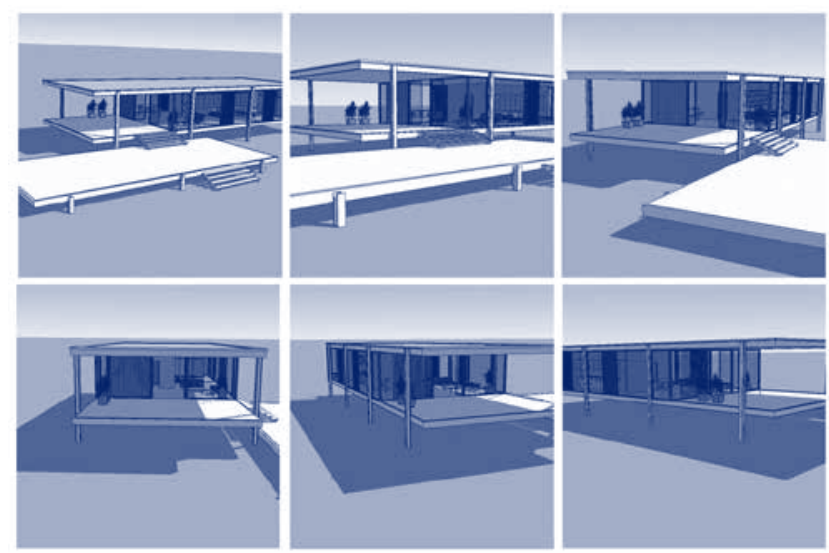

Figura 2: Imágenes de una secuencia de imágenes de una animacion

conjunto de imágenes. Tres parámetros que se proponen para las imágenes, con base a un análisis previo de folioscopios existentes, son: formato cuadrado, velocidad de 5 cuadros por segundo y 50 imágenes.

3. Test de la secuencia de imágenes como GIF animado: a partir de las imágenes generadas, es necesario un test de la animación generada por estas imágenes. Se propone la utilización de un software de desarrollo de GIF animado, el AnimateGif, para hacer el montaje de la secuencia de la animación.

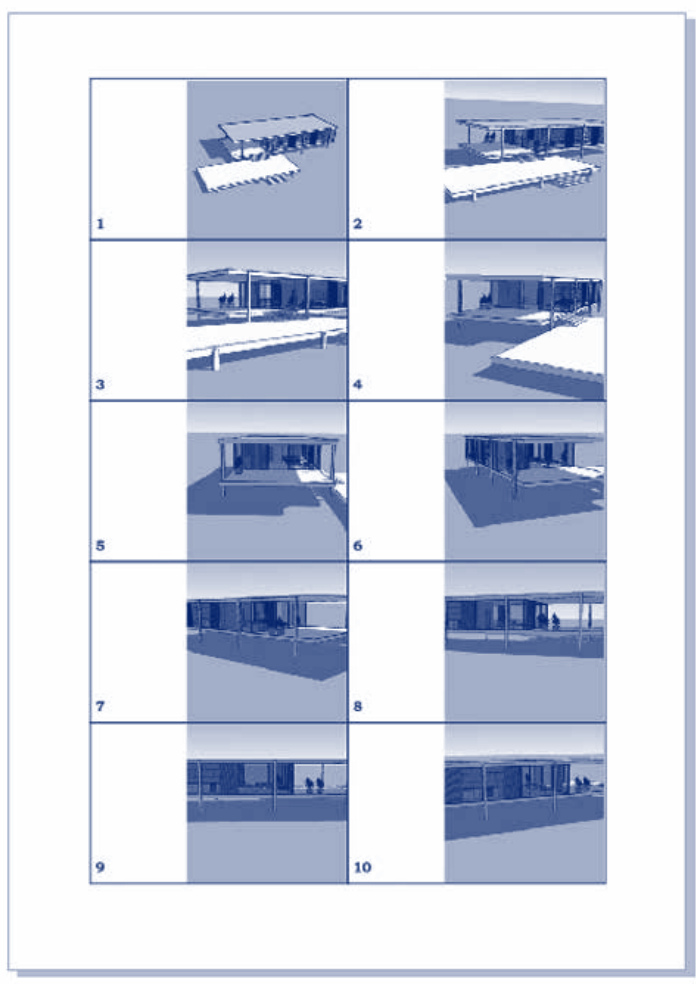

Figura 3: Organización de las imágenes para impresión del folioscopio
4. Organización e Impresión del folioscopio: para el montaje efectivo del folioscopio, las imágenes estáticas necesitan ser organizadas en hojas de formato A4 para facilitar su impresión. En esta organización se define el formato final de las hojas del folioscopio, para el cual, con base a un análisis anterior de folioscopios existentes, se propone los siguientes parámetros: formato rectangular con la mayor dimensión igual a 1,6 veces la dimensión de los lados de la imagen y utilización de números de identificación de la secuencia de las hojas.

\section{Ejemplos de Folioscopio a partir de una Animación Digital}

Para el desarrollo de los ejemplos de los folioscopios, el estudio utilizó un modelo tridimensional desarrollado en Sketchup, de la Farnsworth House del arquitecto Mies van der Rohe. El modelo utilizado fue una composición de cuatro modelos obtenidos de un banco de modelos tridimensionales digitales denominado 3D Warehouse.

Con este modelo fueron seguidas las cuatro etapas propuestas por el método de visualización analógica de animaciones digitales:

1. Definición de Keyframes: fueron creadas 11 escenas que corresponden a 11 keyframes en la animación digital. Estas escenas fueron utilizadas para definir los puntos de vistas principales (keyframes), y así permitir la creación de la interpolación entre las cámaras. Los parámetros de animación fueron configurados con las siguientes informaciones: tiempo de transición entre escenas igual a 1 segundo y tiempo de retraso entre escenas igual a cero. Con relación al tipo de apariencia del modelo, fueron definidas cuatro formas distintas: líneas regulares con fondo blanco, texturas con colores como acuarela y con sombreado, texturas con colores y con sombreado, líneas irregulares con fondo blanco.

2. Desarrollo de la secuencia de imágenes estáticas: con la animación definida, fueron exportadas las imágenes correspondientes a la animación. Los parámetros utilizados en estas imágenes fueron: velocidad de 5 frames per second (fps), formato de archivo .JPG y dimensión 394x394 pixels. La dimensión fue elegida a partir de la definición en un software de edición de imagen, de una imagen de $5 \times 5 \mathrm{~cm}$ con resolución de 200 pixels/inch, una resolución

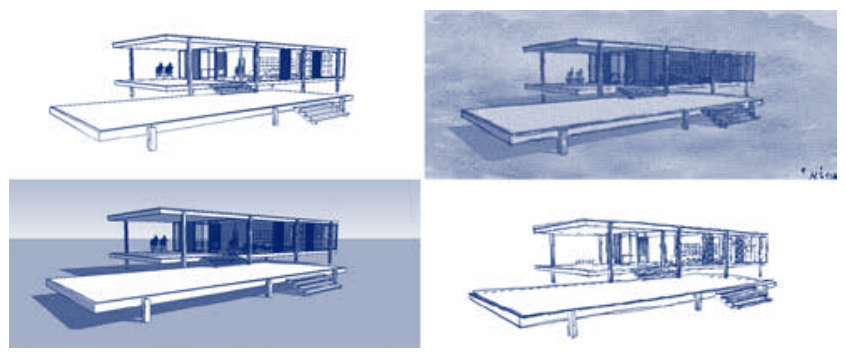

Figura 4: Modelos del Sketchup utilizados en el desarrollo de los ejemplos 


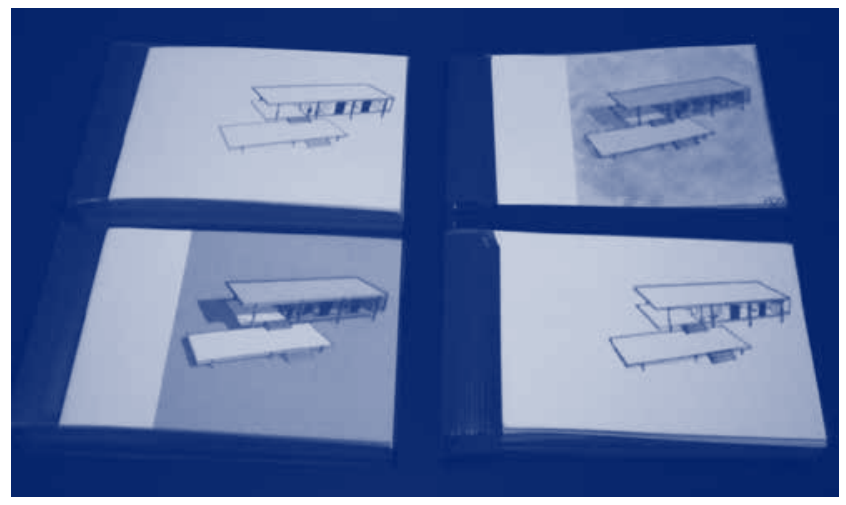

Figura 5: Folioscopios desarrollados como ejemplos del método propuesto

viable para impresión, la cual definió una imagen con $394 \times 394$ pixels.

3. Test de la secuencia de imágenes como GIF animado: las 11 escenas definidas exportaron 52 imágenes. Así fue necesario eliminar dos imágenes para organizar el folioscopio con 50 imágenes. Con el objetivo de no interferir en la animación desarrollada, fueron elegidas la primera y la última imagen para eliminación. Con las 50 imágenes definidas, se utilizó el software AnimateGif para montaje de la secuencia en formato de GIF. Además de la secuencia de imágenes, la única información que este software necesitó fue es el tiempo de retraso entre las imágenes en milisegundos, que para una velocidad de animación igual a 5 fps fue definido como $200 \mathrm{~ms}$.

4. Organización e Impresión del folioscopio: Para organización del folioscopio fue elegido un software de ilustración vectorial, en el cual fueron organizadas 5 páginas en formato A4, con diez imágenes en cada página. La organización de las imágenes siguieron los siguientes parámetros: formato rectangular con dimensión igual a $8 \times 5 \mathrm{~cm}$, imagen posicionada a la derecha y numeración en el lado izquierdo.

\section{Conclusiones}

El objetivo de este estudio fue proponer un método para la utilización de la técnica de animación tradicional, el folioscopio, como artificio de visualización analógica para movimientos desarrollados en medio digital.
En este sentido, los datos obtenidos con los ejemplos desarrollados en el presente estudio señalan que primeramente es posible tener la representación del movimiento en representaciones en papel, y que estos movimientos pueden ser generados a partir de un modelo tridimensional digital.

De este modo, tenemos en los folioscopios una alternativa para visualización de contenidos de animación digital, sin la exigencia de la utilización de un equipamiento electrónico.

Sin embargo, además de esta alternativa de visualización, lo que este estudio demostró principalmente fue la posibilidad de elaboración de representaciones con movimiento, mismo con la utilización de un medio analógico.

\section{Referencias}

Arnheim, R (2008). Arte y Percepción Visual: Psicología del ojo creador. Título original: Art and Visual Perception. A Psycology of the Creative Eye (1954). Traducción de María Luisa Balseiro. Madrid: Alianza Editorial.

Bloomer, K. (1982). Cuerpo, memoria y arquitectura. Título original: Body, Memory, and Architecture. Traducido por: María Teresa Muñoz Jiménez. Madrid: Blume Ediciones.

Comalada, A. (2008). Un folioscopio poético. In: Educación y biblioteca, Año 20, n. 168. Madrid: Asociación Educación y Bibliotecas Tilde.

Dupeyrot, G (1981). Flip story. London, p. 33-35. Bon-À-Tirer, 33.

Heidrich, F.; Redondo, E. (2011). El uso del Medio Digital y el Predominio de las Representaciones Planas y Estáticas. In: IX International Conference on Graphics Engineering for Arts and Design, 2011, Rio de Janeiro. Expressão Gráfica Conexôes entre Ciência, Arte e Tecnologia. Rio de Janeiro: UFRJ.

Júnior, A. (2005) Arte da animação. Sáo Paulo: Editora Senac.

Monedero, J. (1999) Aplicaciones informáticas en arquitectura. Barcelona: Ediciones UPC.

Montes Serrano, C. (1992) Representación y Análisis Formal: Lecciones de análisis de forma. Valladolid: Universidad de Valladolid, Secretariado de Publicaciones.

Norberg-Schulz, C. (1998). Intenciones en Arquitectura. Título original: Intensjoner i arkitekture. Versión castellana de Jorge Sainz Avia y Fernando Gonzalez Valderrama (1967). 2a edición. Barcelona: Editorial Gustavo Gili.

Sainz, J. (2005) El Dibujo de Arquitectura: Teoría e historia de un lenguaje gráfico. Madrid: Editorial Reverté. (Primera Edición, 1990). 